\title{
La estética más allá del arte: A propósito de Gilles Deleuze
}

\author{
Aesthetics beyond Art: About Gilles Deleuze
}

\author{
Laura Llevadot ${ }^{*}$
}

Universidad de Barcelona, Barcelona, Espanha

\section{Resumen}

Este trabajo lleva a cabo un análisis de las críticas que la estética de Deleuze ha recibido y que se cifran en la imposibilidad de comprender las prácticas actuales del arte contemporáneo a través de su planteamiento. Por el contrario se tratará de demostrar cómo en realidad la estética deleuziana supone una superación del concepto de arte, por lo que no sólo su planteamiento no es moderno ni conservador, sino que permite salir del paradigma clásico en el que el arte contemporáneo sigue aún preso.

Palabras clave: Arte. Estética. Kant. Rancière. Osborne. Experiencia.

\section{Abstract}

The aim of this essay is to analyze the critics that Deleuze's aesthetics has been object in regard of his impossibility to understand contemporary artistic practices. On the contrary I will show how deleuzian aesthetics allow us to overcome the modern concept of art which is still in the core of contemporary practices.

Keywords: Art. Aesthetics. Kant. Rancière. Osborne. Experience. 


\section{Introduction}

A menudo sucede que la potencia de un pensamiento genera acólitos acríticos tanto como críticos voraces, que surgen a un tiempo glosadores de la obra del maestro y maestros menores prestos a disputarle el lugar de autoridad. Ocurre que junto a los repetidores sumisos hay también quien no aguarda a exhumar el cadáver para poder decir su contra. Hay la crítica y hay el seguidismo ciego, pero a menudo en ninguno de ambos flancos se plantea el problema que estaría por pensar. Sin duda ocurre esto también con Deleuze. Basta recordar el libro de Badiou articulado sobre unas cartas que Deleuze le había prohibido publicar (BADIOU, 1997), pero que al morir éste Badiou no pudo resistir darlas a conocer para hacer valer su dudosa interpretación de esta obra fundamental. Sin embargo los vaivenes más o menos banales de la vida de las ideas no debieran hacernos pasar por alto aquello hacia lo cuál apuntan algunos de ellos. Más allá de la consabida pelea de gallos en la que se enzarzan críticos y creadores persiste a menudo el rastro de una pregunta que debiera ser tomada en consideración. Y en el caso de Deleuze, y en concreto en el caso de lo que podríamos llamar su estética, parece relevante cuestionar, como lo hacen sus críticos tanto mayores como menores, la inscripción en el presente de su pensamiento estético, esto es, la posibilidad o no de pensar el arte de hoy con Deleuze o gracias a él.

Deleuze es sin duda de aquellos autores que abren una mirada inédita, que generan una poderosa máquina para captar de un nuevo modo los fenómenos más diversos. Si él es uno de los pocos filósofos contemporáneos que merecen este nombre es por haber articulado una conceptualidad que permite pensar fenómenos políticos, estéticos, éticos, u ontológicos, de un modo completamente diferente a como hasta ahora se había hecho, con una riqueza y unos matices que pocas filosofías procuran. También ocurre esto con su modo de presentar la estética, pero es cierto que algo chirría cuando se compara su pensamiento estético con la realidad del arte a él coetáneo. Deleuze escribe sobre música, pintura, cine,... y sin embargo apenas unas palabras sobre arte contemporáneo, esto es, justo sobre aquellas prácticas "que vienen a 
ocupar hoy el lugar de la pintura" (RANCIÈRE, 2012, p. 32). Apenas unas pocas palabras en toda su obra, se buscarán en vano, sobre ese arte que hoy tiene lugar en los museos y galerías que así lo ocasionan. Probablemente sea esta constatación la que ha hecho sospechar y reaccionar a críticos mayores de la obra estética de Deleuze como lo puedan ser Peter Osborne o Jacques Rancière. Y en ambos el diagnóstico parece coincidir: "la estética de Deleuze funciona como medio para restaurar la estética tradicional" (OSBORNE, 2010, p. 28), afirma Osborne en un intento de reivindicar el arte conceptual denostado por Deleuze, o en terminología más acorde con la historia de la filosofía, Rancière apunta a un lugar semejante: "Deleuze cumple el destino de la estética supeditando toda la potencia de la obra a lo sensible puro" (RANCIÈRE, 2002, p. 211). Aquí radica el problema de la estética de Deleuze. Conocemos sus trabajos sobre cine, sobre Bacon y la pintura en general, sobre literatura. No hay desperdicio en cada uno de sus fértiles análisis, y sin embargo, hay aquí un problema a plantear en relación al significado mismo de lo estético y de lo artístico, algo a lo que sus críticos no dejan de apuntar. Para comprender aquello que en la estética de Deleuze chirría al tratar de pensar al arte contemporáneo habrá que seguir al menos hasta cierto punto la estela de sus críticos. Esta será pues nuestra tarea que en lo que sigue se articulará entorno a las siguientes cuestiones: 1) ¿hasta qué punto el pensamiento de Deleuze permite comprender las derivas del arte contemporáneo? Esta sería la primera pregunta que querríamos abordar aquí, y a la que Peter Osborne responderá negativamente: "la obra de Deleuze no da cuenta del problema al que se enfrenta el arte contemporáneo" (OSBORNE, 2010, p. 451), trataremos de vislumbrar el por qué. 2) En segundo lugar, sin embargo, cabría quizás invertir la pregunta y plantear si no será a caso el arte contemporáneo el que habiendo renunciado a la estética y a la creación es él quizás el que no está a la altura del pensamiento de Deleuze, el que no daría cuenta de aquello que Deleuze entiende por arte y por estética. A algo de esto parecería apuntar José Luis Pardo en un artículo sobre la politización del arte que también quisiéramos abordar. 3) Finalmente, habría que poder plantear la cuestión de una estética segunda o quizás de una estética más allá del arte, algo que 
podría extraerse de los trabajos de Deleuze sobre cine, allí donde la crítica del arte contemporáneo al uso, ese que tiene lugar en los museos de arte contemporáneo, es sustituida por algo tan banal como la crítica cinematográfica, la crítica de ese arte de masas que precisamente por serlo quizás sea el único del que nos está permitido esperar el abandono definitivo del concepto de arte, probablemente ya obsoleto, y su sustitución por la estética, logro poco atendido que podría procurar el trabajo de Gilles Deleuze. Veamos en estos tres movimientos: las derivas del arte contemporáneo, la estética desde el punto de vista de Deleuze, y el caso del cine como ejemplo de superación del concepto de arte, el modo cómo quizás Deleuze habrá respondido de antemano a sus críticos al tiempo que habrá abierto un nuevo territorio para pensar el arte hoy. Ni restauración de la estética tradicional, como Osborne pretende, ni cumplimiento de la estética, al decir de Rancière, sino superación de la idea misma de arte, puesta en crisis definitiva del arte como valor en sí, puesta en valor de una estética más allá del arte, de una estética para la que el concepto moderno de arte, con su lastre de mercancía y objeto museístico o de galería, ha devenido caduco y que una óptica deleuziana permitiría substituir por algo mucho más importante: la cuestión de la experiencia, y habría entonces que plantearse si todavía sería lícito concebirla como "experiencia estética".

Vayamos ahora punto por punto para tratar de vislumbrar aquello que en la estética de Deleuze desbordaría el concepto mismo de arte.

\section{Deleuze y el arte contemporáneo}

Para poder responder a la cuestión de hasta qué punto la estética de Deleuze permite comprender algo del arte contemporáneo, deberíamos en primer lugar tratar de situar eso que llamamos "arte contemporáneo". La tarea no es sencilla porque presuponer que el arte contemporáneo es aquel que se da, por ejemplo, en el siglo XX y XXI, sucediendo temporalmente al arte moderno, y este al arte clásico, y este a su vez al arte renacentista y barroco, etc... sería justamente aceptar que siempre ha existido eso llamado arte y que este ha tenido diversas 
etapas de evolución. Pero sucede que tanto la obra de Deleuze como el post-estructuralismo en general nos enseñan a comprender que el tiempo no es ni ha sido nunca lineal, que esta temporalidad evolutiva es una recreación ficticia de un imaginario temporal teleológico, la imagen de un tiempo lineal en el que se situarían los acontecimientos, se superarían formas de pensamiento y expresión, y unas formas remitirían a las anteriores hasta encontrar su origen, en el caso del arte quizás en eso que se ha dado en llamar "arte primitivo". Pero si algo puso en cuestión el pensamiento francés contemporáneo, Deleuze a la cabeza (DELEUZE, 1972), fue la imagen de esta linealidad histórica la cual tiene una fecha de nacimiento y por lo tanto también de caducidad, esta imagen del tiempo que la modernidad se encargó de establecer y que Hegel acabó de perfeccionar al hacerla pasar por el devenir del espíritu absoluto para el que finalmente el arte tendría que morir. Para poder hablar hoy de arte contemporáneo en un sentido contemporáneo y no moderno habrá entonces que repetir el gesto foucaultiano por excelencia y que no es otro que afirmar, como Foucault lo hace en Las palabras y las cosas a propósito del concepto de "hombre" (FOUCAULT, 1993, p. 375), que el arte es una invención reciente. A esta tarea se encomienda exhaustivamente el libro de Larry Shiner La invención del arte (2014). Lo que Shiner muestra en este texto es que el arte tiene apenas tres siglos de existencia, que el arte, tal y como lo entendemos hoy, como objeto separado portador de una experiencia estética, nació entre el siglo XVIII y XIX. No es que antes no hubieran pinturas, esculturas, música, danza, etc... es que todos esos fenómenos estaban vinculados a un contexto del que extraían su sentido, ya fuera religioso, político o económico, pero no tenían sentido en sí mismos separados de su contexto. Hay momentos impagables en el análisis que Shiner lleva a cabo, como cuando se narra el modo como se escuchaba en los salones la música del mismísimo Motzart, sin que nadie atendiera a ella, entre charlas, risas y bebida. Costó grandes esfuerzos y nuevas disposiciones físicas de las salas el poder llegar a crear un público silencioso dispuesto a escuchar música en los términos de quien atiende y hace una experiencia con la obra de arte. La creación de la conducta estética del público se formó al mismo tiempo que el concepto de arte como 
esfera separada y autónoma (SHINER, 2014, p. 187-191). Es por ello que el arte empieza justamente allí donde la creación es arrancada de su contexto, allí donde algo que llamaremos a partir de ahora "obra" se aísla de su lugar de inscripción y deja de tener un valor religioso o decorativo. Para que esto suceda tienen que haber emergido ciertos elementos que tendrán lugar justamente en los albores del s. XIX como son la aparición del museo, del mercado, y del discurso estético. Como dice Rancière en otro lugar "Para que haya arte se precisan una mirada y un pensamiento que lo identifiquen. Y dicha identificación supone un proceso complejo de diferenciación." (RANCIÈRE, 2012, p. 15). En este proceso de diferenciación la estética consistirá inicialmente en ese discurso que establece lo que el arte es, pero justamente en la medida en que la obra llamada artística procura una "experiencia estética" que Kant caracterizará como desinteresada y contemplativa. Ocurre, sin embargo, que para que dicha experiencia estética se dé tiene que haber aparecido el Museo y los salones, hoy las galerías, que aíslan la obra y la dotan de valor artístico. Por eso puede afirmar Jean-Louis Déotte que "el museo es el origen de la estética" (DÉOTTE, 1993), porque sólo hay experiencia estética allí donde la obra aparece aislada y autónoma. A partir de este momento será necesario también un mercado que dote de valor al objeto artístico y con él aparecerá la figura del artista como aquel creador que liberado ya del mecenazgo vende su obra en un mercado y a unas instituciones que la valoran en función de su capacidad o no de producir experiencia estética. A esto es a lo que se refiere Shiner cuando apunta que:

Nadie, entre Platón y Schiller, se enfrentó al problema del Arte y la sociedad en esta forma tan general, porque no existía el concepto de Arte como un dominio distinto o un subsistema social cuya relación con la sociedad precisara ser conceptualizada. Sólo después de que las bellas artes hubieran sido construidas como un conjunto de disciplinas canónicas e instituciones especializadas que se reificaron como un espacio autónomo, fue posible preguntarse por la función que el dominio del Arte debía desempeñar en el seno de la sociedad. (SHINER, 2014, p. 303) 
Teniendo en cuenta pues que el arte es ese invento reciente que aparece allí donde se da el museo, el mercado y la experiencia estética, se comprende porqué Peter Osborne en El arte más allá de la estética va a definir el arte contemporáneo en función del gesto de re-apropiación del significante arte que este lleva a cabo, ya que lo que va a determinar su contemporaneidad es el hecho de ser antiestético. Lo que caracteriza el arte contemporáneo, según la perspectiva de Osborne, es justamente el hecho de rechazar de cuajo la experiencia estética, y ello por dos motivos. En primer lugar porque el elemento estético de la obra no consigue explicar su especificidad. La obra de arte contemporánea no se reduce a sus elementos estéticos (materiales, composiciones, etc..), sino que a menudo tienen también e incluso pesan más elementos de otro orden como lo puedan ser sus funciones cognitivas, elementos semánticos, sociales o políticos. Las sillas de Joseph Kosuth, por poner un ejemplo, no extraerían su valor artístico de sus características estéticas y materiales sino antes bien de su dimensión ontológica. Esto es especialmente cierto en lo que atañe al arte conceptual que es el paradigma del que parte Osborne:

“El arte contemporáneo demostró, de muchas y nuevas maneras y con relación a toda una serie de diferentes formas de materialidad, el modo en que la estética, tanto en su sentido antiguo como en el kantiano (el de sensibilidad y el de juicio reflexivo puro), forma parte de, y sin embargo, no consigue explicar la especificidad ontológica del arte. El concepto estético de arte confunde una de sus muchas condiciones con el todo. Confunde la necesaria apariencia estética del arte con el fundamento de su producción de significado autónoma." (OSBORNE, 2010, 52)

El arte conceptual sería aquel que encarna de manera más clara esta tensión anti-estética del arte contemporáneo y prueba de ello es que la estética, como discurso acerca del gusto o de lo sensible, no alcanza a poder explicar este tipo de arte tan radicalmente desmaterializado y sin embargo tan significativo desde un punto de vista ontológico, que es el que defiende Osborne. Además hay 
un segundo motivo fundamental por el cual el arte contemporáneo rechazaría reducirse a su elemento estético y es el hecho de que es precisamente lo sensual y estético de la obra lo que la liga indefinidamente a su carácter de mercancía. El arte moderno, pero también el arte de vanguardias, se vincula a la exposición de mercancías y a la publicidad como bien muestran hoy todos los museos de arte moderno de nuestras grandes ciudades en las que el turismo artístico y cultural es un valor en alza. Podemos comprar bolsos impresos con cuadros de Klimt o Kandinsky sin distinción y de cada ciudad visitada el turista se lleva su selfies con la pintura de rigor o el póster para el salón de su casa. Cuando un crítico de arte actual como Jorge Luis Marzo se ensaña con la obra de Miquel Barceló (MARZO, 198788) (y podría hacerse con la de Kieffer y tantos otros artistas contemporáneos que siguen apostando por la materialidad de la pintura) lo hace en el mismo sentido en el que se denuncia que el valor estético de la obra es necesariamente funcional al capital y no aporta nada desde un punto de vista político u ontológico. El arte contemporáneo que se comprende como antiestético, cuyo paradigma sería para Osborne el arte conceptual y post-conceptual, recoge entonces el legado duchampiano. La obra de arte antiestética ya no considera el medio como una categoría ontológica para definirse. Ser pintor, escultor, cineasta, etc... no garantiza que lo que sea haga sea arte (de hecho apenas se pinta ya en el marco del arte actual y los museos de arte contemporáneo casi no contienen ya pinturas ni esculturas). Para que lo sea la obra deberá resistir ontológicamente a su mercantilización estética, y ello a través de una desmaterialización, pues lo que la obra antiestética hace en todo caso con su dimensión sensual es un uso crítico de los materiales estéticos que son necesarios pero nunca suficientes para definirla como obra de arte. Así las cosas, se comprende la crítica de Osborne a Deleuze: su estética no sólo no permite comprender el arte conceptual, de ahí la crítica al mismo que aparece en Qué es la filosofía (DELEUZE-GUATTARI, 1993, p. 200), sino que además su filosofía del arte, en la medida en que está basada en la sensación y en los elementos estéticos de la obra, 
funciona como medio para restaurar la estética tradicional y se inscribe dentro de un movimiento general con aires de época: “cierto conservadurismo cultural que es el reverso del radicalismo filosófico y político de la filosofía francesa contemporánea, o por decirlo de otra manera, de la filosofía francesa después del 68." (OSBORNE, 2010, p. 456). El hecho de que Deleuze se interese todavía tanto por la pintura, cuando ésta prácticamente ha desaparecido del mapa del arte contemporáneo, y de que una de sus obras estéticas mayores sea sobre un artista como Francis Bacon, una rareza en el mundo del arte anglosajón y que según Osborne Deleuze afrancesaría con el fin de insertarlo en la tradición artística de las vanguardias nacionales y continentales, y distanciarlo de su opositor neoyorquín que dictará a partir de ahora las tendencias anti-estéticas del arte contemporáneo, son pruebas suficientes del desfase de la estética de Deleuze respecto a los planteamientos teóricos del arte actual.

Por otra parte hay una segunda crítica a este pensamiento estético que Osborne comparte con Rancière, y es la indistinción entre la experiencia estética que procura la naturaleza y aquella que aportaría la obra de arte, confusión de origen ya kantiano pero que justamente por ello advierte del lugar en el que se localiza el posicionamiento estético de Deleuze. Contrariamente a Adorno que trataría de seguir aquí a Hegel, Deleuze se sitúa en la concepción de "el arte como estética", esto es en la herencia kantiana que al centrarse en la cuestión de lo sensible "no puede distinguir el arte de la naturaleza" (OSBORNE, 2010, p.43), y por lo tanto no puede ofrecer criterio alguno de lo que diferencia ontológicamente el arte de los otros objetos que procuran experiencia. Con ello la autonomía del arte es negada y la obra, definida por su carácter estético, se desvanece y confunde con los fenómenos naturales.

Ambas críticas a la estética de Deleuze, su limitación a los elementos estéticos de la obra en tanto ésta se piensa desde lo sensible, y la negación de la autonomía del arte, sitúan el pensamiento de Deleuze en el marco de la estética más tradicional, aquella que desde un cierto conservadurismo cultural seguiría ofreciendo criterios al mercado para la fetichización y mercantilización de la obra. 
También para Rancière, Deleuze adolecería de este conservadurismo en la medida en que seguiría concibiendo la estética en su modalidad tradicional, como discurso que dice lo que el arte es en función de su capacidad para histerizar lo sensible ${ }^{1}$, en lugar de concebirla como un régimen de reparto de lo sensible, como el modo mismo como el poder se organiza y divide la calidad de la experiencia entre los que sí tendrían acceso a ella y los que no. Habría sin embargo que hacer justicia a Deleuze y cuestionar la validez de estas críticas, habría quizás que ceder la palabra a Deleuze justo allí donde éste se plantea la cuestión kantiana de la experiencia estética, verdadera matriz de la problematización actual del arte contemporáneo.

\section{La estética de Deleuze}

Si bien es cierto que en Deleuze no se halla una investigación directa sobre lo que se ha dado en llamar arte contemporáneo, aunque haya que esperar a los que han recogido su herencia para encontrar reflexiones deleuzianas entorno de obras como la de MattaClark (ALLIEZ, 2013) o Lygia Clark (ROLNIK, 2006), aún así habría que coger las aguas desde más abajo y tratar de vislumbrar el modo como Deleuze replantea la cuestión kantiana de la estética hasta el punto de no sólo no restaurar la estética tradicional sino justamente quebrarla y probablemente superarla (SMITH, 1996). Habría entonces que atender a una enigmática afirmación de Deleuze que aparece como de pasada en uno de los apéndices de Lógica del sentido, donde se puede leer:

Rancière ha publicado por el momento lo siguientes textos sobre la estética de Deleuze: Jacques Rancière sur l'esthétique deleuzienne : «Existe-t-il une esthétique deleuzienne », en E. Alliez (éd.), Gilles Deleuze. Une vie philosophique, Paris, Les Empêcheurs de penser en rond, 1998, p. 525-536 ; « Deleuze, Bartleby et la formule littéraire », en J. Rancière, La Chair des mots. Politiques de l'écriture, Paris, Galilée, 1998, p. 179-203 ; « D'une image à l'autre? Deleuze et les âges du cinéma », en Rancière, J., La Fable cinématographique, Paris, Galilée, 2001, p. 145-163. Así como « La peinture dans le texte », en Le destin des images, Paris, La Fabrique, 2003, p. 81-102.

Rev. Filos., Aurora, Curitiba, v. 29, n. 46, p. 179-198, jan./abr. 2017 
“La estética sufre de una dualidad desgarradora. Designa, de un lado, la teoría de la sensibilidad como forma de la experiencia posible; del otro, la teoría del arte como reflexión de la experiencia real. Para que los dos sentidos se reúnan, es preciso que las condiciones de la experiencia en general devengan a su vez condiciones de la experiencia real; la obra de arte, por su parte, aparece entonces realmente como experimentación." (DELEUZE, 1989, p. 262)

La tarea de la estética de Deleuze va a consistir en superar esta "dualidad desgarradora" entre un concepto de estética entendido como "teoría de la sensibilidad" y otro que se comprende como "teoría del arte". Deleuze está haciendo referencia aquí a la dualidad kantiana. Esto es, de una parte, al concepto de estética trascendental que aparece en la Crítica de la razón pura, donde ésta designa una teoría de la sensibilidad que en tanto trascendental vale como forma de toda experiencia posible, la estética entendida como el análisis del espacio y el tiempo, de esas formas de la sensibilidad que determinan la experiencia de cualquier objeto empírico. Y de otra parte, ese concepto de estética que va a reaparecer en la Crítica del juicio, y que va a sentar las bases de una teoría del arte comprendida como reflexión, no ya de la experiencia posible, sino de la experiencia real de los objetos naturales y artísticos que producen el sentimiento de lo bello y lo sublime. Nada más lejos del planteamiento de Deleuze que defender esta segunda posición de la estética que se reduciría finalmente a una suerte de filosofía del arte (CASTILLA, 2016, p. 200), es decir a un discurso y planteamiento categorial que determina lo que el arte es y si un objeto se aviene o no a ello. La crítica de Osborne parecería atribuir a Deleuze esta posición, sin embargo lo que se plantea en el fragmento citado es justamente lo contrario. "Para que los dos sentidos se reúnan" alude al modo en que Deleuze va a permitirnos comprender a partir de ahora aquello que la obra de arte es. Obra de arte será entonces aquella en la que los dos sentidos del término estética se reúnen, aquella en la que las "condiciones de la experiencia en general" devienen "condiciones de la experiencia real", es decir que lo que define la obra de arte es que ésta sea capaz de transformar las condiciones de posibilidad de nuestra experiencia, de ahí su necesario carácter experimental. Desde este punto de 
vista, lo que permite que las condiciones de la experiencia real (las que Kant reservaba a lo bello) devengan condiciones de la experiencia posible es que la obra de arte sea capaz de modificar dichas condiciones, que la obra nos haga sentir y experimentar más allá de lo que es comúnmente "posible", más allá de lo general, de modo tal que al hacerlo se rompa el corsé de nuestro "sentido común", de nuestra capacidad común de sentir. La obra de arte es experimental porque amplía el campo de la experiencia posible, porque produce una "sensación", y no ya un sentimiento reconocible. ¿Qué es una sensación en terminología de Deleuze? Aquello que ocurre cuando algo (me) llega y yo devengo (otro), la modificación que se produce en un sujeto a partir de la recepción de un objeto, lo que le ocurre al sujeto que en ese mismo momento deja de serlo cuando el objeto, en lugar de objeto de reconocimiento, deviene la ocasión de un encuentro. Es a esta transformación del sujeto a la que Deleuze alude cuando cita a Cézanne: "Está pasando un minuto del mundo, no lo conservaremos sin volvernos él mismo" (DELEUZE y GUATTARI, 1994, p.170). La finalidad del arte consistirá entonces en producir un "bloque de sensaciones" tal que sea capaz de modificar nuestras condiciones normales de percepción que sólo nos permiten reconocer el objeto que las produce en lugar de llevarnos más allá de él. Es en este sentido que Deleuze supera la dualidad kantiana (SMITH, 1996), aun si su planteamiento sigue siendo kantiano en su raíz. En cierto modo puede afirmarse que "Deleuze parece no romper con el gran movimiento de fondo que entraña la filosofía moderna del arte. Lo lleva más bien a su culminación pero de una manera extraña, paradójica, por una suerte de sobrepuja y de elevación a la potencia $n$ de esta misma sensibilidad" (MENGUE, 2013, p.139). Así, parecería posible afirmar con Rancière que el análisis de Deleuze se inscribe en el destino de la estética moderna ligada a lo sensible (RANCIÈRE, 2002, p. 211) en la medida en que, siguiendo el análisis que Rancière lleva a cabo en El malestar de la estética, el concepto separado de "arte" tal y como lo conocemos desde la modernidad ligado a la experiencia de lo sensible sólo tendría lugar con la aparición del "régimen estético del arte", es decir, de aquel régimen de experiencia para el cual el arte ha dejado de ser imitación, donde el "saber hacer" de las bellas artes ya no 
rige la calidad de los productos, en aquel régimen en el cual la obra de arte se definiría por su singularidad sensible. Si esto es lo propio del régimen estético del arte -la aparición de la obra de arte entendida como "sensible puro" separada de su contexto, aislada ya en el museo como diría Déotte-, entonces parecería que el pensamiento de Deleuze seguiría inscrito en esta concepción moderna de la estética y de la obra. Si embargo, si atendemos a esa superación del dualismo kantiano que Deleuze trata de hallar en la obra de arte, aquella por la cual la obra deviene un bloque de sensaciones capaz de modificar las condiciones de posibilidad de nuestra experiencia, entonces hay que acordar con Mengue que la pertenencia de Deleuze al destino moderno de la estética es solo aparente, ya que en realidad lo excede por un movimiento paradójico de sobrepuja de lo sensible estético. ¿En qué consiste esta sobrepuja que excede la comprensión moderna de la obra de arte? En el hecho que la obra de arte, justo porque es experimental y reúne los dos sentidos kantianos del término estética, no trabaja ya con percepciones y afecciones sino con preceptos y afectos. La obra de arte, como bloque de sensaciones, aparece ahí donde se eleva la percepción a percepto, y por su parte las afecciones o sentimientos se depuran de toda subjetividad y se alzan a la condición de afectos, y todo ello ocurre dibujándose un plano de composición donde conviven los afectos y los perceptos. La obra de arte rompe con los clichés y las opiniones, con los modos comunes de percibir y de sentir, y descubre tras una percepción subjetiva y particular, un precepto, algo como "un paisaje antes del hombre": las colinas de Faulkner, la estepa de Tolstoi, el océano de Melville y Acab... al igual que las afecciones vividas se elevan a afectos, a devenires no humanos (DELEUZE-GUATTARI, 1993, p. 168). La literatura está llena de estos hermosos descubrimientos, una novela que no nos habla ya del amor sino que tras este sentimiento común y aburguesado descubre el afecto de una fraternidad entre lobos por ejemplo, o un texto de Clarice Lispector como La pasión según G.H. donde tras el asco de una mujer solitaria se asoman los afectos divinos de una cucaracha. Y no es necesario que los personajes de una novela vivan afecciones extraordinarias, Thomas Wolfe puede mostrar a través de las opiniones miserables y estúpidas de las gentes de Catawha, 
detrás de su manía de discutir, todo el fragor de sus vidas olvidadas, el secreto de su soledad, el desierto que las atraviesa y que ya no es un sentimiento (el enfado que lleva a la discusión, por ejemplo) sino un afecto (el paisaje yermo de una vida). El arte tendría por función entonces descubrir afectos desconocidos o mal conocidos, añadir variaciones nuevas al mundo, enriquecer, quebrar, atravesar, las formas comunes de nuestra sensibilidad. Y esta composición, que provendría de un movimiento de desterritorialización que iría del cliché a los afectos y preceptos, y a su vez de una re-territorialización de los mismos en el plano de composición que los permite mantenerse juntos y resistir a su desplome, se abriría a su vez a una desterritoialización posible, un "cosmos" de sensaciones puras, un "unheimlich" más allá de la casa o el territorio que el arte tiende a reconstruir. Esto ocurre también con las artes visuales, y Deleuze y Guattari pueden comprender el arte abstracto como este intento de ir más allá de los clichés y alcanzar una sensación pura: "Como cualquier pintura, la pintura abstracta es sensación y sólo sensación” (DELEUZE-GUATTARI, 1993, p. 185). El arte abstracto trataría de ganar la sensación del concepto, pintar ya sólo el plano de composición atendiendo a una sensibilidad cósmica, hacer del color liso que vibra el mismísimo precepto, pintar el color de antes del hombre. Por eso pueden afirmar Deleuze y Guattari que ningún arte ha sido jamás representativo porque el arte siempre tiende a ir más allá de la representación, la opinión, el reconocimiento, el cliché. Esa es su función, ofrecernos la posibilidad de agujerear el paraguas del sentir común que nos limita y empobrece nuestras vidas.

Esta concepción de la obra de arte en Deleuze, como experimentación que modifica las condiciones de posibilidad de la experiencia, tiene dos consecuencias importantes respecto a la cuestión que aquí nos atañe: su supuesto conservadurismo al que aludía Osborne, y su pertenencia al régimen moderno de la estética, según Rancière. En primer lugar, desde la posición de Deleuze el arte conceptual, que Osborne defendería como paradigma del arte contemporáneo, sufre carencias difícilmente superables: 
“El arte conceptual se propone una desmaterialización opuesta, por generalización, instaurando un plano de composición suficientemente neutralizado [...] para que todo adquiera un valor de sensación reproducible al infinito: las cosas, las imágenes o los clichés, las proposiciones, una cosa, su fotografía a la misma escala y en el mismo lugar, su definición sacada del diccionario. No es nada seguro sin embargo, en este último caso, que se alcance así la sensación ni el concepto, porque el plano de composición propende a volverse informativo, y porque la sensación depende de la mera opinión de un espectador al que pertenece la decisión eventual de materializar o no, es decir, de decidir si aquello es o no es arte" (DELEUZE-GUATTARI, 1993, p. 200)

Es decir, que justo por su condición anti-estética el arte conceptual devuelve el plano de composición a la mera información. En lugar de elevarse de los sentimientos y percepciones a los afectos y perceptos, hace girar la dirección de la obra de la sensación a la opinión, allí donde el espectador debe decidir conceptualmente si aquello que se le propone es arte o no lo es. La obra se propone entonces como espacio de interpretación, en lugar de experimentación, de modo que se malogra todo el trabajo que nos debía permitir ampliar los límites de nuestra experiencia. Tanto esfuerzo para volver a encontrarse con las afecciones y percepciones de siempre parece el trabajo baldío de buena parte del arte actual. A algo de ello aludía el artículo de Jose Luis Pardo sobre la politización del arte (PARDO, 2014). En este caso el blanco de la crítica no es ya el arte conceptual sino las derivas actuales del gesto duchampiano que impregnan de politicidad el arte contemporáneo. El arte político más activista, o por ejemplo el arte decolonial o relacional al que Pardo no alude pero que se comprendería en esta tensión, presentarían para este autor el mismo problema que Deleuze planteaba al arte anti-estético y lo acercarían peligrosamente a la propaganda política en el medida en que plegaría la obra a las condiciones de lo real en lugar de abrir lo real sensible a nuevas condiciones. A pesar del conservadurismo cultural que sin duda exhala el artículo de Pardo en cierta medida da en la clave para comprender que la politicidad del arte, desde la perspectiva de Deleuze, no pasa tanto por el contenido o intención explícita de la obra cuanto por su condición experimental. Es decir que la obra de arte, por el solo hecho de serlo, realiza ya una 
pequeña revolución silenciosa frente al orden dominante sin reducir los afectos y perceptos a la mera denuncia, es decir, sin devolver la obra al cliché y a la opinión. Desde el punto de vista de la estética deleuziana lo conservador en arte consistirá justamente en remitir la obra a la mera opinión, a la representación y el reconocimiento, porque allí donde esto ocurre no ocurre nada, se deja al sujeto intacto sabiendo lo que ya sabía, sin que se produzca en él ninguna modificación de sus condiciones de percepción ni devenir alguno que lo arranque de su consabido lugar. Lo conservador, desde este punto de vista, será eliminar del arte su componente estético porque sólo ahí, en el ámbito del sentir, el de los perceptos y afectos, puede producirse una revolución del pensar, sólo sintiendo de otro modo aprenderemos quizás a pensar de otro modo, y tal vez si fuera todavía posible, a vivir de otro modo ${ }^{2}$. Esto es a lo que ya apuntaba desde el principio el empirismo trascendental de Deleuze.

\section{La estética más allá del arte}

La segunda cuestión a retomar será entonces aquella a la que aludía Rancière cuando afirmaba que esta concepción sensible del arte de Deleuze remitía al destino moderno de la estética. Pero el régimen estético del arte es aquel en el que aparece el concepto de obra de arte separada y autónoma, cuando es justo esto lo que en la estética de Deleuze no se da. En su concepción de la obra como experimentación hay una indistinción radical y voluntaria entre arte y naturaleza. Como ha señalado Sauvagnargues: “El arte no es un rasgo antropomórfico, no es lo propio del hombre" (2005, p. 196). La construcción de un plano de composición cargado de afectos y perceptos no es una actividad exclusivamente humana, sino que "el arte empieza tal vez con el animal, o por lo menos con el animal que delimita un territorio y hace una casa" (DELEUZE-GUATTARI, 1993, p. 185). El ejemplo del pájaro de los

2 A esta cuestión apunta el trabajo de Mireille Buydens (2005) en el que se pone en cuestión el vitalismo de Deleuze en virtud de su presentismo estético. 
bosques lluviosos de Australia que cada mañana deja caer del árbol hojas, las tumba por su otra cara para que el color contraste con la tierra, y después se pone a cantar encima de ellas imitando notas de los cantos de otros pájaros, sirve a Deleuze y Guattari para mostrar que la modificación de las condiciones de posibilidad de la experiencia es un acontecimiento ontológico y cosmológico, que en nada se corresponde con ese intervalo historiográfico al que Rancière llamaría "régimen estético del arte". Pero a su vez, la indistinción del arte y la naturaleza en lo que atañe a la experiencia estética no se debe a que desde esta perspectiva se niegue la autonomía del arte, tal y como Osborne planteaba, sino que lo que se niega es la reducción de la estética a la "teoría del arte", es decir, a su deriva hegeliana, puesto que en realidad toda verdadera experiencia, esto es, aquella que modifica las condiciones de posibilidad de nuestra percepción y afección, será siempre estética en su sentido amplio, y no la procurará únicamente ese tipo de objetos a los que por determinación histórica y con el beneplácito del mercado hemos coincidido en llamar artísticos. Un paisaje, un pájaro, una visión espiritual pueden tener la misma fuerza de transformación que un cuadro de Cézanne. Con esta ampliación de la experiencia estética al ámbito de la naturaleza lo que sí va a desaparecer sin embargo es el concepto mismo de arte. Los trabajos de Deleuze sobre cine en La imagen-movimiento y $\mathrm{La}$ imagen-tiempo dan cuenta precisamente de esta posición estética para la que el término arte ha devenido obsoleto. Sin duda es tan artístico un film de Eisenstein o Leni Riefensthal como uno de Rossellini o Godard, o por contemporizar un poco, uno de Kaurismaki. Lo que les diferencia no es su mayor o menor contenido artístico (pues estaremos de acuerdo en que tanto El acorzado Potemkin como La fuerza de la voluntad pueden ser consideradas, y así lo han sido, obras de arte) sino el hecho de que los primeros pertenecen a la imagen-movimiento, esto es, a una concepción del cine basada en el montaje y en el esquema sensorio-motor, es decir, en el modo común de percibir, mientras que los segundos introducen en el lenguaje cinematográfico la imagen-tiempo, esto es, un cine de vidente en el que los personajes son incapaces de reaccionar y cambiar situaciones, justo porque son presos de situaciones ópticosonoras puras, visiones que antes que la acción narrada por el montaje 
muestran el intersticio entre plano y plano, hacen visible lo invisible, como diría Klee, y por lo tanto modifican nuestra percepción. La mirada perdida de Ingrid Bergman en Europa 51 al ver salir los obreros de la fábrica ("me parecía estar viendo condenados a muerte") tantas veces comentada, constituye una de estas situaciones óptico-sonoras puras que el cine nos dio a ver (DELEUZE, 1987, p. 64). Quizás la apuesta estética de Deleuze pueda medirse antes que en sus textos sobre pintura, en su análisis y clasificación topológica de la imagen cinematográfica, porque en estos trabajos a Deleuze le importa muy poco lo que sea arte y mucho lo que es experiencia, lo que el cine es capaz de hacer con nuestras condiciones de posibilidad de la experiencia. Es por ello que podría decirse que Deleuze, antes que mantener una postura conservadora o culminar la concepción moderna del arte, a lo que realmente nos invita es a abandonar la pregunta por lo que el arte sea. Ante una película, una performance, o una intervención artístico-política en un barrio desfavorecido ya no debiéramos preguntarnos si eso es arte o no lo es, pregunta moderna vinculada al museo y el mercado, a la fechización de la mercancía, sino si eso que se propone modifica o no nuestras condiciones de experiencia posible, y si esto no ocurre tampoco valdrá la pena experimentarlo por mucho que le llamemos arte. La politización del arte a la que apelaba Benjamin al final de su célebre texto (BENJAMIN, 2008, p. 85) encuentra en Deleuze una nueva respuesta que no ha sido contemplada ni por Osborne ni por Rancière: una estética más allá del arte enseña a abandonar la pregunta por lo que el arte sea, puesto que este significante condena la obra a ser mercancía y por lo tanto a su despolitización estructural, y abre la posibilidad de sustituirla entonces por otras mucho más existenciales y políticas: de entre todo lo que se nos propone ¿qué vale la pena ser experimentado? ¿qué me libera de mi subjetividad normativa? ¿qué modifica las condiciones comunes de mi percepción y mi afectividad? Quizás entonces a partir de estas preguntas, y gracias a Deleuze, la estética entendida como la superación del dualismo kantiano que viene determinando la concepción del arte contemporáneo ganará de una vez la partida al arte fetichizado. 


\section{Referencias}

ALLIEZ, E. Défaire l'image. De l'art contemporaine. Paris: Les presses du réel, 2013.

BADIOU, A. Deleuze: la clameur de l'être. Paris: Hachette, 1997.

BENJAMIN, W. "La obra de arte en la época de su reproductibilidad técnica", Obras. Libro 1/ v.2, Madrid: Abada, 2008.

BUYDENS, M. Sahara. L'esthétique de Gilles Deleuze. Paris: Vrin, 2005.

CASTILLA, A. “Une philosophie artiste. Réflexions sur l'histoire (souterraine) de l'esthétique française contemporaine". In LLEVADOT, L.; RIBA, J.; VERMEREN, P. (Ed). Barcelone pense-t-elle en français? La lisibilité de la philosophie française contemporaine. Paris: L'Harmattan, 2016. p. 193-206.

DELEUZE, G. “A quoi reconnaît-on le structuralisme?” In: F. CHATELET (éd.), Histoire de la Philosophie, t. VIII: le XX' $\mathrm{X}^{\mathrm{e}}$ siècle, Paris, Hachette, 1972. p. 299-335.

DELEUZE, G. La imagen-tiempo. Estudios sobre cine 2. Barcelona: Paidós, 1987. DELEUZE, G. Lógica del sentido. Barcelona: Paidós, 1989.

DELEUZE, G; GUATTARI, F. ¿Qué es la filosofía?. Barcelona: Anagrama, 1993. DÉOTTE, J-L. Le musée, l'origine de l'esthétique. Paris: Harmattan, 1993.

FOUCAULT, M. Las palabras y las cosas. Madrid: Siglo XXI, 1993.

MARZO, J. L. "Barceló, Barcelona (Sobre Miquel Barceló)", Àrtics, n. 7, 1987-1988.

MENGUE, P. "De l'affect sans pathos à la figure sans visage. Problèmes d'esthétique deleuzienne". In: JDEY, A (Ed.), Gilles Deleuze, la logique du sensible. Esthétique et clinique, Lille: Ed. De l'incidénce, 2013.

OSBORNE, P. El arte más allá de la estética. Ensayos filosóficos sobre arte contemporáneo. Murcia: CENDEAC, 2010.

PARDO, J. L. “¿Politización del arte? Ensayo sobre la falta de memoria”, Input, 1, 2014, pp. 17-22. 
RANCIÈRE, J. “¿Existe una estética deleuziana?”, en ALLIEZ, E. (dir.), Gilles Deleuze. Una vida filosófica. Santiago de Cali (Colombia): 2002, p. 211.

RANCIÈRE, J. El malestar en la estética. Buenos Aires: Capital intelectual, 2012. ROLNIK, S. ¿El arte cura? Barcelona: MACBA, 2006.

SAUVAGNARGUES, A. Deleuze et l'art. Paris: PUF, 2005.

SHINER, L. La invención del arte. Una historia cultural. Barcelona: Paidós, 2014. SMITH, D.W. "Deleuze theory of sensation: Overcoming the kantian duality". In: PATTON, P. (Ed.) Deleuze. A critical Reader. Malden (Massachussetts): Blackwell Publishers, 1996. p. 29-56.

Recibido: 13/10/2016

Recebido: 13/10/2016

Aprobado: 03/02/2017

Aprovado: 03/02/2017 